\title{
Rastreando el sonido. Cartografía de la sonoridad en el arte contemporáneo desde su origen hasta la Asturias del siglo XXI
}

\author{
Marcelino García Sedano \\ Universidad San Francisco de Quito
}

RESUMEN:

No cabe duda de que, dentro de las numerosas y diferentes manifestaciones artísticas del arte contemporáneo, el arte sonoro, permanece muchas veces en desventaja con el resto de disciplinas en cuanto a presencia, representación y difusión. Podemos decir que el arte sonoro, entendido en un sentido estricto, sigue siendo una disciplina minoritaria que no ha recibido la debida atención por parte de la crítica, la historiografía y las instituciones. En Asturias, durante los primeros años del siglo XXI ha habido una importante escena que ha explorado las posibilidades del sonido desde una perspectiva creativa. El objetivo de este artículo es reseñar las manifestaciones más importantes dentro de ese contexto y dar un repaso a las características que hacen que estas puedan ser consideradas arte sonoro, así como la evolución y diversas facetas del término.

\section{PALABRAS CLAVE:}

Arte sonoro, Asturias, arte contemporáneo, instalación sonora, paisaje sonoro.

\section{ABSTRACT:}

Without doubt, beyond the variety of artistic manifestations in Contemporary Art, Sound Art often remains at disadvantage of other disciplines in terms of presence, representation and dissemination. We can assure Sound Art, in its strictest sense, is still a bordering discipline that has not attracted sufficient attention from the art world-system. Since the beginning of the 21st century Asturias represents an important scene that has explored the possibilities of sound with a creative perspective. This paper focus on reviewing the most important manifestations originated on this context and also elucidates the features which distinguish them as artwork, their evolution and different facets of the term.

\section{KEYWORDS:}

Sound Art, Asturias, contemporary art, sound installation, soundscape. 
1. Hacia una aproximación al concepto de arte sonoro.

Las características específicas del arte sonoro han propiciado que se relacionara de forma compleja con la Historia del Arte. Sin pertenecer a ningún movimiento ni discurso o periodo concreto, la definición de sus propiedades y dimensiones teóricas, ha sido algo complejo e impreciso motivado por la tradicional división de las artes. Es por ello, que antes de enumerar y definir las manifestaciones artísticas asturianas que tienen que ver con el sonido, se debe proceder a definir qué entendemos por arte sonoro.

A pesar de que la naturaleza sonora de algunas obras desde una perspectiva contemporánea del arte puede encontrarse desde las vanguardias ${ }^{1}$, el concepto "arte sonoro" comienza a emplearse desde finales de los años setenta cuando el sonido en las obras se utilizaba como recurso para acentuar el carácter conceptual de la misma. De igual forma, podemos valorar como arte sonoro, ampliando la noción, aquellos proyectos que parten de la utilización del sonido en sus discursos con el afán de experimentar con sus posibilidades, no sólo conceptuales, sino también perceptivas o sensoriales. Por eso, en Centroeuropa, artistas visuales, poetas y performers utilizaron lo sonoro acuñando el concepto Sound Art, directamente ligado a la relación de la tecnología con el sonido. Sin la tecnología, este no puede manifestarse o moldearse con fines creativos. Contemporáneo a este concepto, en Alemania se acuñó un término más complejo y preciso que difiere en forma del de Sound Art, ya que sound puede aludir también a ruido. Este término es Klangkunst, donde klang alude a lo musical y aludiría también a aquellas manifestaciones donde lo sonoro puede simultanearse con lo visual. Es bajo esta característica que se plantea la existencia de una nueva dimensión estética más específica dando cabida a la concepción más popular de arte sonoro.

\footnotetext{
Hay una larga tradición de presencia del sonido en el arte desde manifestaciones artísticas en las vanguardias con ejemplos diversos como la poesía sonora del cubofuturismo o dadaísmo de artistas como Kurt Schwitters o Raoul Hausmann, los experimentos ruidistas del futurismo y la posterior música experimental, músique concrète y las incursiones en el arte de autores como John Cage, Max Neuhaus, Alvin Lucier o Fluxus por citar algunos.
}

Partiendo de la definición de David Warner y Christoph Cox en su libro "Audio Culture: Readings in Modern Music", el arte sonoro es: "un término general para obras de arte enfocadas en el sonido y que son a menudo producidos para museos y galerías"2. Bajo este amplio paraguas, la mayor dificultad a la que nos enfrentamos con esta particularidad artística, es la de delimitarla como objeto de estudio. Es prácticamente inútil concebirla como una disciplina artística independiente de otras manifestaciones, ya que su estudio fluctúa entre la historia del arte y de la música, dos ámbitos académicos independientes que rara vez confluyen. Por esa razón, el término arte sonoro, ya por sí mismo, implica ese divorcio: el arte vincula esas manifestaciones con lo visual y el término sonoro con lo musical ${ }^{3}$. Si además apelamos a las clasificaciones de las artes de forma tradicional, a esta división entre lo visual y lo musical, se suma la división entre las artes del tiempo, cine, música por ejemplo y las del espacio, como pueden ser las bellas artes ${ }^{4}$.

Es desde la música cuando se plantea en los años cincuenta la redefinición de los conceptos de oyente, compositor y artista lo que permite unir las dimensiones sensibles de lo visual y lo sonoro, académicamente separados por tradición ${ }^{5}$. Esta debilidad ontológica subraya, por un lado, esa difícil clasificación, pero por otro, da cabida a cualquier manifestación artística que contenga sonido. De esta forma, Max Neuhaus incluye como arte sonoro la música, esculturas cinéticas, instrumentos accionados por el viento o tocados por el público, arte conceptual, efectos sonoros, lecturas grabadas de prosa o poesía, obras de arte visual que también hacen sonido, pinturas de instrumentos musicales, autómatas musicales, películas, vídeos,

COX, Christoph y WARNER, David (eds.). Audio Culture: Readings in Modern Music. Continuum Publishing, Nueva York, 2004, pág. 415.

3 PARDO SALGADO, Carmen. "En los arenales del arte sonoro,", en Arte y politicas de Identidad, Vol. 7 / Diciembre 2012, pág. 16.

4 MOLINA ALARCÓN, Miguel. "Reconstruir, recrear o revisitar la resonancia del arte sonoro de las vanguardias (¿versión o perversión?)”, en MOLINA ALARCÓN, Miguel [et. al], Ruidos y Susurros de las Vanguardias. Reconstrucción de obras pioneras del Arte Sonoro (19091945). Editorial de la UPV, Valencia, 2004, pág. 16.

5 MAIRÉ, José Luís. “Qué es el arte sonoro?”, en FONTAN DEL JUNCO, Manuel, IGES, José y MAIRÉ, José Luís (eds.) Escuchar con los ojos. Arte sonoro en España,1961-2016, Fundación Juan March, Palma, 2016, pág. 28. 
exhibiciones tecnológicas, reconstrucciones acústicas, programas interactivos de ordenador que producen sonido, etc. ${ }^{6}$. Esta restricción, que parte de intentar encontrar la identidad del género en el propio medio, hace que Neuhaus llegue incluso a dudar de que se pueda hablar de forma autónoma del arte sonoro como tal ya que parte de la idea de que, en el arte, el discurso no sólo depende del medio ${ }^{7}$. Este hecho, se subraya también por la evolución de proyectos que diluyen las fronteras entre lo musical y lo sonoro, dando si cabe, una nueva visión más independiente de las restricciones de la música en cuanto a estructura, discursos etc.

Según Ramón González Arroyo, se puede crear basándose en una organización espacial donde el sonido define espacios y formas como si se tratase de un objeto plástico que se recrea en su propia transversalidad y en la búsqueda de un absoluto plástico. Por lo tanto, conviene tener en cuenta que el arte sonoro es un arte híbrido que surge de la mezcla de disciplinas y soportes diversos, con especial hincapié en los tecnológicos, lo que ha propiciado una aproximación a partir del concepto o perspectiva del arte de los medios ${ }^{8}$. No es hasta la década de los 80 cuando se populariza el término de arte sonoro reivindicando su autonomía y no sin gran inconformidad por parte de artistas y académicos, discrepancias reforzadas por la dificultad de exhibirlo dentro de los esquemas tradicionales del cubo blanco.

Parece ser que lo más difícil en el estudio de esta disciplina es precisamente definir sus características y esencia. José Luís Mairé en el catálogo de la exposición "Escuchar con los ojos. Arte Sonoro en España, 1961-2016”, la más exhaustiva muestra que se ha realizado sobre arte sonoro en España hasta el momento dice: "como toda categoría artística leída desde un punto de vista historiográfico simple, narrada mediante la sucesión de hitos, artistas fetiche y

GARCÍA SEDANO, Marcelino. Arte, ciencia y tecnología. Tercera cultura y creación artística en la Asturias del siglo XXI. Tesis doctoral, Universidad de Oviedo, Oviedo, 2017, pág. 300

7 NEHAUS, Max. "Sound Art?", en Volume: Bed of Sound. P.S.1 Contemporary Art Center, Nueva York, 2000. Information en la página web del artista. Recuperado el 13 de febrero de 2017. http://www.max-neuhaus.info/soundworks/soundart/SoundArt.htm

$8 \quad$ IGES, José. "El sonido como arte. Raíces y evolución del arte sonoro en España”, Conferencia Escuchar con los ojos. Arte sonoro en España, 1961-2016, Madrid 18 de Octubre de 2016, pág 19. terrenos teóricos inamovibles o prefigurados, el arte sonoro ha encontrado y encontrará siempre un enfrentamiento directo con su definición. Sus objetivos académicos, expositivos o comerciales persiguen y pretenden un origen, inexistente por otra parte, que nos permita justificar de una manera lo más clara posible qué es el arte sonoro" $"$.

\section{La música experimental, un puente hacia} la dimensión artística de lo sonoro.

La música experimental ha sido de gran importancia a la hora de diluir la frontera entre lo musical y lo artístico, dando pie a nuevas formas de expresión que sin duda tuvieron gran influencia en la escena artística asturiana contemporánea ${ }^{10}$. Repasar la historia del arte sonoro implica sin duda tener presente las revisiones del concepto que desde el ámbito de la música se han realizado de los mecanismos tanto académicos como historiográficos, buscando una manera más libre de aproximarse al fenómeno musical. El origen de la experimentación en la música se remonta al siglo XIX con la búsqueda de experiencias sinestésicas por parte de compositores como Debussy, Scriabin, o Schönberg quienes apoyándose en la relación entre lo visual y lo sonoro, abrieron terreno para la intermedialidad e interdisciplinariedad del acto creativo.

John Cage planteó, en un inicio, entender la música como una "organización del sonido" 11 ya que este hecho abría la posibilidad de propuestas musicales que hiciesen énfasis en el proceso, la improvisación, lo aleatorio y nuevas formas de interacción con el público, resultando en productos mucho más libres, azarosas e indeterminadas ${ }^{12}$. A su vez, y debido a esa liber-

9 MAIRÉ, José Luís. “Qué es el arte sonoro?”, opus cit. pag. 29

10 La región siempre ha tenido una gran presencia de manifestaciones musicales experimentales, sobre todo dentro de géneros cercanos a la música electrónica, hecho que ha evolucionado en el tiempo hacia la celebración de eventos de gran renombre nacional e internacional como el LEV Festival o Laboratorio de Electrónica Visual.

11 CAGE, John. "The future of music: credo", en CAGE, John. Silence. Lectures and writings of John Cage. Wesleyan University Press, Nueva Inglaterra, 1973 pág. 3.

12 NYMAN, Michael. Música experimental. De John Cage en adelante. Documenta Universitaria, Gerona, 2006, pp. 22-25. 
tad, la música experimental desde su inmaterialidad permitió establecer nuevas reflexiones acerca de la obra artística como objeto, cuestionando la autoría o la capacidad autónoma de la música como género y aproximándose a lo artístico desde un mayor vínculo con lo visual. Esta indeterminación del medio se concreta en el concepto de intermedia que representa una ruptura histórica de los medios mediante el cual es posible localizar algunas manifestaciones de la música experimental a caballo entre la música y otras disciplinas. Partiendo del carácter mixto de la naturaleza artística de lo sonoro, Pierre Schaffer padre de la música concreta, concebía esta como un espacio creativo que se movía entre el mundo del intelecto y las ciencias que dan dimensión al sonido como la acústica, la cibernética o la psicología ${ }^{13}$.

Lo experimental consistía en probar metodologías y estructuras presentes en otras disciplinas como el teatro, la danza, la poesía o las mismas artes plásticas y esto se puso en práctica en los cursos organizados por Cage entre los años 1956 y 1960 en The New School for Social Research de Nueva York. Estos cursos planteaban un espacio de trabajo interdisciplinar con coreógrafos, actores, artistas plásticos y una variada presencia de campos de la creatividad. Es en este contexto cuando se acuña realmente el término “música experimental”, aquella que, según Cage, produce resultados imprevisibles ${ }^{14}$. Una vez que Cage consolidó la idea iniciada por Russolo de que cualquier sonido podía ser utilizado en música, la música ya no tenía que intentar parecer música. La organización o conceptos como autoría dejaron paso a la improvisación, al ruido y la disonancia y a la libertad de los sonidos que no debían responder ya a una organización concreta implicando una transformación en el concepto de composición, ejecución y audición, posibilitando propuestas musicales con una mayor tendencia hacia lo artístico. A esto se suma la separación definitiva entre lo que es la percepción sonora y el hecho musical en sí, adquiriendo lo sonoro, una fuerte carga conceptual.

13 HODGKINSON, Tim. "An interview with the pioneer of the musique concrète". Entrevista online. Recuperada el 21 de febrero de 2017. http://www.ele-mental.org/ ele_ment/saidctdid/schaeff er_interview.html

14 MADERUELO, Javier. "Hijas de una misma madre", en FONTAN DEL JUNCO, Manuel, IGES, José y MAIRÉ, José Luís (eds.) Escuchar con los ojos. Arte sonoro en España,1961-2016, Fundación Juan March, Palma, 2016, pág. 60
La llegada de las tecnologías electrónicas a lo sonoro propició delimitar lo que se llamó la materialidad de la música. El componente electrónico en forma de grabación o de sintetizadores, modificó las posibilidades expresivas del sonido. Por un lado, esto tuvo lugar con las grabaciones que derivaron en la música concreta y por otro, con la llamada música electrónica, que surgía y se fortalecía de las grandes posibilidades de ordenación y manipulación del sonido que estos avances brindaban. Esta última cambió la manera de entender la música, aportando una dimensión nueva de sonidos que evocaban otros mundos y sobre todo cambiando la manera de componer, pasando de la partitura a una forma más física de hacerlo, modelando el sonido.

No cabe duda de que la relación de lo sonoro con las artes plásticas y los avances de la música en el sentido de la experimentación, son las dos direcciones principales que se pueden trazar para entender los antecedentes de lo que hoy podemos concebir como arte sonoro.

\section{Antecedentes del arte sonoro en España y Asturias.}

Como no podía ser de otra forma, la introducción de la dimensión sonora en el arte español y sobre todo en Asturias, fue particular. Es a partir de los años sesenta cuando en España comienzan a verse nuevos lenguajes artísticos donde lo conceptual adquiere peso. Dentro de este proceso y al contrario que en otras latitudes, lo lingüístico pierde fuerza y cede paso a una experimentación con las características conceptuales del sonido desde una perspectiva interdisciplinaria, pero no de forma específica hacia lo sonoro ${ }^{15}$. Por lo tanto, era más común ver obras que contenían sonido que obras estrictamente sonoras.

En cuanto al ámbito de la música experimental, bastante significativo, cabría reseñar a Juan Hidalgo, fundador del Grupo Zaj o Luís de Pablo, quienes, habiendo viajado al festival de Ferienkurse für Neue Musik, de Darmstadt, pudieron traer a España nuevas ideas resultantes de su contacto con Cage, Stockhausen o

\footnotetext{
5 FONTÁN DEL JUNCO, Manuel. "Escuchar con los ojos, o la cara B del arte contemporáneo en España”, en FONTAN DEL JUNCO, Manuel, IGES, José y MAIRÉ, José Luís (eds.) Escuchar con los ojos. Arte sonoro en España,1961-2016, Fundación Juan March, Palma, 2016, pág. 16.
} 
Kagel entre otros. Es en la década de los años cincuenta cuando surgen asociaciones artísticas musicales como Nueva Música y Tiempo y Música, destinadas también a explorar las posibilidades de la experimentación musical.

El interés por lo conceptual y el avance hacia lo interdisciplinar, fue acentuado por la atracción por el arte y la ciencia de la década de los años 60 y principios de los 70, ejemplificada por la actividad del Seminario de Generación Automática de Formas Plásticas, dentro del Centro de Cálculo de la Universidad de Madrid o los Encuentros de Pamplona de 1972. El caso de Centro de Cálculo de la Universidad de Madrid es muy importante para la historia del arte contemporáneo español por diversas razones, una de ellas la precocidad con la que experimentaron con las computadoras como herramientas creativas demostrando una gran modernidad para la época y consolidándose como uno de los orígenes más sólidos del arte tecnológico en España y, por otro lado, por incluir de forma también prematura, sonoridades y experimentaciones artísticas con el sonido en una de sus exposiciones más importantes: "Generación automática de formas plásticas y sonoras" con la presencia notable de autores como Josep María Mestres Quadreny, Manuel Barbadillo o el mismísimo John Cage ${ }^{16}$.

De la misma forma, los Encuentros de Pamplona, supusieron un gran impulso para el arte conceptual, característica que estimulaba la exploración de las capacidades del sonido desde la investigación artística, aspecto que tuvo bastante presencia en el evento gracias a la inclusión de artistas como Joan Brossa, John Cage, David Tudor, Luís de Pablo, Antoni Muntadas, Wolf Vostell, etc.

Las metodologías de la música concreta, las grabaciones de campo y en definitiva la producción y grabación de sonido con fines experimentales destacaron durante la década de los 80 en España donde se generaron sobre todo espacios de intercambio centrados en la autoproduc-

\footnotetext{
6 Nacido en 1966 con el apoyo de IBM y SAE, el Centro de Cálculo pronto acogió dentro de su paraguas tecnológico las inquietudes creativas de Florentino Briones, subdirector quien desarrolló durante 5 años el Seminario d Generación Automática de formas Plásticas. Dentro de este contexto se organizaron muestras como la anteriormente citada y "Formas Computables" o seminarios de gran importancia internacional donde se contó con la presencia de Negroponte, Abraham Moles, Max Bense $y$ en el ámbito intelectual español, Juan Navarro Baldeweg, Eusebio Sempere o Luís de Pablo.
}

ción y distribución de materiales sonoros que en muchos casos desembocaron en la formación de colectivos artísticos donde se realizaban colaboraciones no solo entre artistas sonoros, sino también con otras disciplinas. Dentro de este panorama destacan los nombres de Diseño Corbusier, Comando Bruno, Esplendor Geométrico, Mataparda y otros ${ }^{17}$. Posteriormente el auge del arte intermedia y tecnológico con la ayuda de internet a partir de los años 90, acogió obras de talante sonoro y facilitó su difusión. De igual forma, las herramientas digitales facilitaron plataformas creativas multimedia evidenciando el poder de las nuevas tecnologías para la creación y difusión de productos culturales.

Como ha ocurrido en diversas manifestaciones del arte contemporáneo, la evolución del arte sonoro en el Principado de Asturias ha sido bastante característico: las primeras manifestaciones sonoras de corte experimental provienen del mundo del rock y tienen lugar en la década de los años 80. En concreto, esta tardía presencia se debe a la utilización e incorporación de grabaciones de campo de una braña asturiana en la canción "Mayu" del grupo Asturcón. Este ejemplo es lo más parecido a ser considerado el primer paisaje sonoro grabado en la región ${ }^{18}$.

Posteriormente, proyectos interdisciplinares basados en el teatro o la performance jugaron con las posibilidades del sonido y la improvisación musical como ocurrió con Equipo Estético Étika makinal (3EM) o Somnium en Mieres o con la composición de collages sonoros como los proyectos Royal Canín, Ulán Bator Trío o Madame Sifón.

El cambio de siglo continuó alejado de las artes visuales con proyectos de experimentación sonora como Mus (Fran Gayo y Mónica vacas), Daniel Romero (Dot Tape Dot), Juanjo Palacios (Mapa Sonoru), David von Rivers (Duga III), Pedro Menchaca (Men Chak) o LCC (Ana Quiroga y Uge Pañeda). Esta escena se vio impulsada por las herramientas digitales que promovían la democratización del discurso sonoro, dotando de gran libertad a los artistas para producir su material e incluso experimen-

\footnotetext{
7 FELIPE, Francisco. "Soportes de edición y canales de distribución de la creación sonora”, en FONTAN DEL JUNCO, Manuel, IGES, José y MAIRÉ, José Luís (eds.) Escuchar con los ojos. Arte sonoro en España,1961-2016, Fundación Juan March, Palma, 2016, pág. 162

18 BALBUENA, Rafael. "Arte sonoro en Asturias”, en Atlántica XXII, № 46, Septiembre de 2016.
} 
tar con él sin necesidad de mediación alguna ${ }^{19}$. El desarrollo de la tecnología del sonido es paralelo a la investigación de las posibilidades creativas del mismo, no solo desde la perspectiva de lo musical.

En Asturias no puede entenderse lo sonoro fuera de la perspectiva del arte neomedial y por supuesto, como ocurre con el desarrollo de este tipo de arte en la región, no se puede obviar la importancia que LABoral Centro de Arte y Creación Industrial ha tenido para el impulso de esta escena. Por lo tanto, hay grandes obras y artistas que han creado y exhibido en la región bajo este paraguas, configurando una escena que, aunque no es muy grande, puede ser considerada sólida y autora de grandes e interesantes proyectos. La intención de este artículo es referenciar los nombres y obras más significativas del arte sonoro asturiano del siglo XXI realizando una aproximación breve a la instalación sonora y al paisaje sonoro como disciplinas más relevantes.

\section{La instalación sonora asturiana}

Retomando el postulado teórico que concibe el arte sonoro desde la contemplación de la materialidad del sonido, podemos considerar la instalación sonora como una expansión de la escultura. El concepto alemán de Klangkunst en oposición al de sound art, permite pensar las manifestaciones sonoras desde una cercanía a lo visual y el desarrollo de una nueva estética que surge de la mezcla de lo visual con lo sonoro $^{20}$. Este territorio intermedio da pie a lo que serán los directos audiovisuales o las instalaciones sonoras.

Algunas de las instalaciones sonoras más significativas de principios del siglo XXI fueron "Los pilares del silencio" (2005) de Paco Nadie, ganadora del premio Astragal y "Lugares para vivir sólo con la imaginación” (2005) de Maite Centol, expuesta en el patio del Antiguo Institu-

19 RAMOS, Ana y JIMÉNEZ, Roc. “Amor digital: Música experimental en la década de los noventa (19922002)", en BLÁNQUEZ, Javier y MORERA, Omar. Loops. Una historia de la música electrónica. Reservoir Books, Barcelona, 2002, pág. 441.

$20 \quad$ PARD0, Carmen. "Klangkunst y sound art: reflexiones y consecuencias”, en FONTAN DEL JUNCO, Manuel, IGES, José y MAIRÉ, José Luís (eds.) Escuchar con los ojos. Arte sonoro en España,1961-2016, Fundación Juan March, Palma, 2016, pág. 87. to. Estas tuvieron lugar dentro del contexto de Arenas Movedizas 2005, un espacio clave para entender la introducción de nuevas disciplinas artísticas en la región. Arenas Movedizas se lleva a cabo en Gijón desde el año 2002 con la ayuda del Área de Juventud del Ayuntamiento de Gijón, el Principado de Asturias, los consejos de Juventud del Principado de Asturias (CMPA) y de Gijón (CMX) y con la incorporación de LABoral desde su creación en 2007. Dirigido por Cristina de Silva y Nacho de la Vega intervenía el espacio público y los lugares más emblemáticos de Gijón con una muestra artística de periodicidad anual. La intención era generar un espacio de intercambio cultural con la ciudad a partir de los espacios públicos, intención que aun perdura porque se sigue celebrando en la actualidad $^{21}$. Ambas instalaciones coincidían en la introducción del concepto de memoria a partir de lo sonoro. En la primera, las fronteras entre autor y la existencia corpórea como memoria se difuminaban y la obra de Centol, planteada en la misma dirección, propiciaba una reflexión a partir de testimonios sonoros, voces anónimas que hablaban del concepto de exilio realizando un viaje entre lo privado y lo público. En este contexto destacaron también "La incómoda sensación de que un autómata guía nuestras vidas. Recuerdos gota”, de Adrián Cuervo y "Aramadillium Vulgare", desarrollada en la antigua residencia de estudiantes de la Universidad Laboral de Daniel Acevedo y Sergio Camacho.

En los primeros años de LABoral existió lo que se llamó "Cubo de Sonido", un espacio y programa de apoyo a disposición de los creadores que trabajaban desde lo sonoro. Desde este interés se promovieron instalaciones sonoras como "Drift" (2007) de Jana Winderen basada en las grabaciones de campo con hidrófonos de diversos ríos o "Montreal Mutado" (20002006), proyecto del afamado artista sonoro español Francisco López basado en una metodología similar a la música concreta absoluta, descontextualizando completamente los sonidos en una búsqueda de la esencia sónica. La performance sonora derivada se llamó "López Inmersive Sound"22.

\footnotetext{
${ }^{21}$ Información en la página web de "Arenas Movedizas" Recuperado el 21 de febrero de 2017. http://arenasmovedizas.org/arenas-movedizas/

22 Información en la página web de LABoral Centro de Arte y Creación Industrial. Recuperado el 15 de febrero de 2017. http://www.laboralcentrodearte.org/es/exposiciones/montreal-mutado
} 
De esta forma, y bajo estos ejemplos, el formato de instalación sonora explota las posibilidades de lo que Schaffer había definido sobre la materialidad del sonido al que concebía como un objeto ${ }^{23}$. Partiendo de esto, la instalación sonora busca esculpir el espacio a base de sonido, propiciando una experiencia inmersiva donde el concepto de tiempo deriva en una especial transformación, disociándose del espacio y dando sentido al concepto de tiempo real ${ }^{24}$.

Una manera más de expresar la plasticidad del sonido, sería la escultura sonora, concepto a caballo entre lo visual y lo conceptual, donde predomina la idea o concepto que tenemos sobre la sonoridad. Esta idea se despliega tanto en su dimensión acústica como visual, repartiendo la importancia que tienen ambos aspectos. Por definición, una escultura sonora puede emitir sonido o en cierta forma estar latente en ella ${ }^{25}$.

"Chopping piano - in C", (2008), del colectivo asturiano Las larvas compuesto por Paco Nadie, Fernando Oyagüez, Jesús García Coronado y Arantxa Hernández, fue una escultura sonora exhibida en LABoral. Aunque el colectivo no se especializó exclusivamente en arte sonoro, incursionó en la disciplina al proponer una instalación compuesta por un piano destrozado cuyo proceso de destrucción es evidenciado al proyectar el sonido de esta acción obtenido previamente con micrófonos de contacto. Esta obra criticaba a la tradición occidental de entender la música desde un prisma ortodoxo, como un producto cultural determinado. De esta forma se produce un juego interesante entre el sonido que potencialmente podría brotar de un piano desde su esencia conceptual, su imagen y el concepto de tiempo ya que la escultura produce un sonido emitido y grabado en este caso en el pasado, enfrentando este con el presente ${ }^{26}$.

23 PICADO FERNÁNDEZ, Vera Y. "Arte y escultura sonora: Del sonido como objeto al objeto sonoro", en Arte y Políticas de identidad, vol. 7, diciembre de 2012, pág. 54.

24 PALMER Daniel. "Contemplative Immersion: Benjamin, Adorno \&t Media Art Criticism”, en

Transformatios. Issue 15. Noviembre 2007, pág. 3. Recuperado el 15 de febrero de 2017.

http://www.transformationsjournal.org/issues/15/article_11.shtml

25 LICHT, Alan. "Sound Art: Origins, development and ambiguities", en Organised Sound 14(1), Cambridge, 2009, pág. 7.

26 "Las Larvas", blog del colectivo. Recuperado el 16 de febrero de 2017. http://laslarvas.blogspot. com/2005_05_01_archive.html
"Visualizando el sonido", fue una exposición realizada dentro del marco del LEV festival del año 2012. Curada por los directores del festival, Cristina de Silva y Nacho de la Vega bajo el formato de una exposición tradicional, reunía piezas artísticas que pretendían, bajo las premisas de las artes plásticas más tradicionales, visualizar el sonido y resolver sus características materiales y conceptuales de forma visual, no solo auditiva. Como corresponde al espíritu del festival, el carácter tecnológico de muchas obras era evidente lo que sumaba a la reflexión de las obras, la presencia y el interrogante sobre los nuevos medios. Obras como "Versus" (2011), de David Letellier, “20Hz” (2011) del dúo británico "Semiconductor", de gran calidad y renombre internacional convivían con dos obras asturianas. Lucía Rivero presentó "Banda sonora para aquel que ha sido dado la vuelta dando la impresión de que fuera a irse" (2011), trabajo que plantea un loop de cinta magnética que a su vez suena y va modificando su sonido según el tiempo pasa y esta se somete al desgaste progresivo. La obra jugaba con el espacio ambiguo entre el concepto de loop físico y el loop sonoro ${ }^{27}$. La otra presencia asturiana fue la obra de Daniel Romero "Qlux Puba, Música para 200 brincadores”(2010 - 2012), presentada con anterioridad en Arenas Movedizas y sobre la que hablaremos más adelante.

Daniel Romero alias .Tape. es una de las figuras más vinculadas al arte sonoro, en múltiples variantes que van desde la música experimental a las instalaciones sonoras y la utilización de métodos de grabaciones de campo. Romero es pionero en la producción de música electrónica experimental en la región, ya que desde finales de los 90 comenzó a componer piezas musicales compuestas de grabaciones de campo y sonidos emitidos por juguetes o dispositivos musicales electrónicos de baja calidad $u$ 8 bit. Pero sin duda, gran parte de su importancia reside en la hibridación del sonido con otras disciplinas. Bajo la fórmula del directo musical, debutó en la edición del año 2003 de Arenas Movedizas con un concierto en el Museo Barjola. Esta faceta le ha permitido desarrollar una carrera bastante prolifica con presencia a través de sellos internacionales como el español Spa.

\footnotetext{
$27 \quad$ Información del proyecto en la página web de Lucía Rivero. Recuperado el 10 de marzo de 2017.

http://www.luciarivero.com/2010/03/soundtrack-forsomeone-who-has-been.html
} 
rk, el estadounidense Other Electricites, Nature Bliss en Japón, los franceses Optical Sound \& Aspic Records, Eglantine Records y el alemán Mira Recs.

Retomando la mencionada con anterioridad dentro del marco de "Arenas Movedizas", "Qlux Puba, Música para 200 brincadores”(2010 2012) es una obra que aprovecha la existencia de unos insectos mexicanos, un tipo de polilla del desierto de Sonora, que habitan dentro de unos frijoles llamados "saltarines". El autor monitoriza los saltos de los mismos y emiten sonidos mediante micrófonos de contacto, completando y ampliando la experiencia estética con luces que se generaban o activaban con ese sonido ${ }^{28}$.

Otra instalación sonora del autor fue "Rapsodia”, en colaboración con Fernando Gutiérrez y expuesta en el stand de ABC en ARCO 2012. Esta obra surge de la colaboración con Plataforma 0 de LABoral marco en el que realizaron una residencia para producir la obra. Partiendo de la combinación con una disciplina artística más clásica como es el dibujo, se construye un mundo con seres que interactúan al sonido de una canción de cuna, reproduciéndose y generando más sonidos mediante sus acciones espontáneas y aleatorias. La obra posee un carácter interactivo muy marcado, pero también alusiones a lo generativo, el azar y a un universo de fantasía ${ }^{29}$.

Otro ejemplo, concebido para el almacén sur de LABoral fue "Silencio" (2010). Esta instalación audiovisual surge de "MADI, Música Avanzada y Discapacidad Intelectual”, unos talleres realizados en Avilés entre finales de 2009 y principios de 2010 que exploraban entre otras cosas, la función pedagógica de lo sonoro y la experimentación musical apoyada por las nuevas tecnologías. La instalación plantea una reflexión mediante contenido audiovisual de las circunstancias únicas de las personas con discapacidad psíquica ${ }^{30}$.

28 Procesando (cap 5) Daniel Romero", video entrevista en la página web de LABoral. Video en Vimeo, 6:18. https://vimeo.com/20847887

29 "Rapsodia, de Fernando Gutiérrez y Daniel Romero, seleccionada para el stand de ABC en ARCO 2012", en arteenlared.com. Recuperado el 29 de marzo de 2017. http://www.arteenlared.com/espana/detodo-un-poco/rapsodia-de-fernando-gutierrez-y-daniel-romero-seleccionada-para-el-stand-de-abcenarco- 2012.htm

30 Información del proyecto en la página web de "LABoral Centro de Arte y Creación Industrial".
Entre el 8 de octubre y el 8 de diciembre dentro del marco del EcoLAB, laboratorio de experimentación con ecología y electrónica abierta, dirige mediante una residencia un grupo de trabajo que explora las posibilidades sonoras y creativas de la intersección entre el arte y la ecología. Para ello impartió talleres metodológicos y prácticos para el desarrollo de grabaciones en la naturaleza y documentaron el sonido de plantas, insectos y animales. Posteriormente dirigió hasta 2015 el LABoratorio de Sonido de LABoral Centro de Arte y Creación Industrial y actualmente es artista asociado del Département Numerique de humain TROP humain CDN de Montepellier, Francia, donde anteriormente fue director.

Desde 2014 hasta 2017, se producen en LABoral varias residencias de artistas que tienen como fin la producción de obra. La iniciativa viene desde el LABoratorio de sonido y el resultado de esas residencias fueron, en el mayor de los casos, instalaciones sonoras. Destacaron algunas internacionales como "Frequencies (light quanta) (2014), [I Can't Fix What You Broke] (2014) de Mark Fell o "Afinando" (2015) de Andrée-Anne Roussel y trabajos de artistas locales, curiosamente provenientes de la música y no del arte como "Paradigma" (2015) de Héctor Sandoval / Tensal y "Mov. Ámate Ur.ox" (2015) de Marta Medina.

\section{El paisaje sonoro, sonidos de la geografía astur}

La producción de Daniel Romero es muy significativa, variada metodológicamente y abundante. Conviene mencionar algunos proyectos en los que ha participado para poder introducir el concepto de "paisaje sonoro" y reflejar la importancia metodológica que posee este terreno creativo basado en grabaciones de campo en la actividad artística asturiana contemporánea.

En 2014, Daniel Romero y un conjunto de artistas asturianos trabajaron en un proyecto llamado "La mina y su sonido". Este proyecto es la evolución lógica de otro realizado en 2013 comisariado por José Manuel Costa en el marco de LABoral y la exposición del LEV Festival, "Visualizar el sonido". En ella varios artistas realizaban un retrato desde lo sonoro del centro

Recuperado el 29 de marzo de 2017. http://www.laboralcentrodearte.org/es/exposiciones/silencio 
de arte. "La mina y su sonido" se circunscribió en el marco de un proyecto más amplio conocido como "Aprendiendo de las Cuencas", dirigido por Nacho Ruiz Allén y Sara López Arraíza. Esta iniciativa, planteaba ver de forma crítica un espacio tan emblemático y complejo desde el punto de vista social y económico como son las cuencas mineras asturianas y una de las facetas desde la que se realizó este análisis fue el sonoro. "La mina y su sonido" fue una exploración a partir de cuatro piezas de la realidad de las minas asturianas ${ }^{31}$. Dirigido de nuevo por José Manuel Costa, Romero presenta una grabación realizada en el Pozo San Fernando en Orillés, destacando el carácter rural que ha adquirido el antes activo pozo minero mediante sonidos de animales y espacios naturales. Completan las obras Edu Comelles con "Pozo Sotón, El Entrego", Oscar de Ávila y su obra sobre el "Pozu Espinos, Turón" y Mind Revolution con la reflexión sobre el "Pozo Candín, La Felguera".

La grabación de campo, base metodológica del paisaje sonoro, es una de los aportes más claros de la música concreta para este género artístico. Este género musical al incorporar sonidos ambientales para generar un nuevo discurso y significado, ha influenciado mucho al arte sonoro y sus diversas metodologías ${ }^{32}$. El desarrollo de las tecnologías de grabación y su carácter portátil facilitaron sin duda este tipo de estrategias creativas y lo más importante, colocaron al sonido grabado al mismo nivel de los sonidos musicales más tradicionales, rompiendo con los convencionalismos musicales y desarrollando lo que se llamará los "discursos concretos" ${ }^{3}$. Pierre Schaffer, padre de la música concreta y apasionado de los sonidos mundanos, definió la práxis de este género musical como el hecho de "recoger el concreto sonoro de dondequiera que procediera y abstraer de él todos los valores musicales que contenía en potencia “"

31 Información del proyecto en la página web de "LABoral Centro de Arte y Creación Industrial”. Recuperado el 24 de octubre de 2018. http://www. laboralcentrodearte.org/es/files/2013/educacion/artesonido/blog/la-mina-y-su-sonido-1

32 COSTA, José Manuel. "Arte Sonoro", en Revista de información y debate sobre arte actual EXIT Express $\mathrm{n}^{\circ}$ 54. Madrid: Editado por Olivares \&t Asociados, S. L, 2010, pág. 19.

33 BEJARANO CALVO, Carlos M. Música Concreta Tiempo destrozado. Universidad Nacional, Bogotá, 2007, pág. 5.

34 SCHAFFER, Pierre. Tratado de los objetos musicales. Alianza Música, Madrid, 2003, pág. 23.
El ejemplo anterior de la mina y su sonido, está directamente relacionado con el concepto de "Paisaje sonoro" y en consecuencia con el de los mapas sonoros, ambos presentes en el arte asturiano. Un paisaje sonoro, debe ser entendido como aquellos elementos audibles característicos de una localización geográfica y que son susceptibles de cambiar dependiendo de la época y la percepción del oyente. $\mathrm{R}$. Murray Schafer, profesor de comunicación, músico y compositor fue el teórico que dimensionó la noción como método para entender el medio sonoro que rodea al ser humano y sus connotaciones culturales. El sonido, resultado de nuestro existir, debe ser estudiado para explicar la vida humana y la sociedad, obteniendo así, importante información al respecto ${ }^{35}$. Para formalizar este interés académico, Schafer fundó desde la Simon Fraiser University en Canadá, los Soundscapes Studies mezclando las ciencias sociales, el urbanismo y algunas ciencias más específicas de lo sonoro como la acústica. La acústica, como ciencia que estudia la relación del sonido con el espacio, se convierte en el principio para entender, aplicar o realizar, un mapa sonoro. Esta herramienta, permite ligar un territorio a un sonido en concreto, siendo estos sonidos, la consecuencia de desarrollos tecnológicos, circunstancias naturales o procesos culturales. La antropología del sonido, consecuencia de estas metodologías, se nutre de la acustemología o mezcla entre acústica y epistemología que pone en relación disciplinas como la sociología, la antropología y la etnografía estableciendo conexiones entre la identidad, la memoria y el lugar ${ }^{36}$.

La realización de una de las actividades fonográficas mas consistente y el desarrollo de mapas sonoros en Asturias se debe a la presencia del artista y músico electrónico navarro afincado en Gijón, Juanjo Palacios (Estella, 1966). El trabajo de mayor envergadura realizado por Palacios en esta dirección es "Mapa sonoru", iniciado en 2009 y vinculado a LABoral desde el 2011. El proyecto, aun en desarrollo aúna actividades de formación mediante talleres abiertos a la ciudadanía con la configuración de un mapa sonoro digital de la región asturiana, fruto en ocasiones, de esa actividad

\footnotetext{
5 ibidem, pp. 57-62.

36 () Sound as a technological medium. Elektronische-artand-music, Londres, 2014, pág. 21. ibídem, pág. 18-21.
} 
formativa. De carácter colectivo y social, además de Juanjo Palacios, otros artistas fonográficos han contribuido a la realización de este proyecto $^{37}$.

"Mapa sonoru", resulta en una suerte de cartografía donde poder escuchar a Asturias en sus múltiples dimensiones, rural, industrial, urbana, quedando representados sus procesos dinámicos de orden sociocultural ${ }^{38}$. Como dice Josep Cerdá: “el espacio público es una composición sonora en transformación y es también un reflejo de los cambios estructurales de la sociedad. Hay una identidad sonora en cada lugar, y ello configura la memoria sonora y el subconsciente colectivo de sus habitantes. Cada ciudad, barrio o calle tienen un ambiente sonoro diferencial que se va transformando $\mathrm{y}$ adaptando en el tiempo. Los límites del cambio y transformación de los sonidos son imprecisos dado que son un reflejo directo de una gran complejidad" 39 .

El trabajo de Juanjo Palacios se completa con numerosos conciertos y obras sonoras en directo y cabe reseñar que desde 2009 preside una plataforma internacional fonográfica llamada "La escucha atenta" donde recoge y coordina los trabajos de numerosos artistas destacando como colaboradores son Edu Comelles y Ángel González.

"Broadcasting Art. Mapeando el paisaje sonoro. Asturias", fue otra aproximación al paisaje sonoro asturiano dentro del marco de "Arenas Movedizas". En colaboración con el prestigioso programa "Fluido Rosa" de Radio 3 y con sede en el Centro de Investigación Artística Ladines, se heredaba el planteamiento del "Taller Broadcasting Art” que pretendía mapear la sonoridad de la geografía española, pero aplicado a la especificidad del ámbito geográfico asturiano esta vez. El resultado de este taller

$37 \quad$ Tal es el caso de Tomás Braña, Luca Rullo, Ana Quiroga y Uge Pañeda (LCC), Santiago Abadía, Javier F. Granda, Los Zapatos del Otro, Ramón del Riego, René de Coupaud, Pelayo Guardado, Óscar de Ávila, Edu Comelles, Carlos de Hita, Eugenia Fernández y Ángel González (Mind Revolution), Etokeè, Javier S. Quirós, Laura Fernández, Rosario de la Fuente, Amado G. Llera, Virginia López, Olaya Fernández Herrero, Francisco Javier Rodríguez, Eulalia Baena, Ot Mas y otros

38 Información en la página web del proyecto "Mapa sonoru”. Recuperado el 12 de febrero de 2017. http://mapasonoru.com/acerca-de.php

39 CERDÁ, Josep. “Observatorio de la transformación urbana del sonido. La ciudad como texto, derivas, mapas y cartografía sonora", en Arte y politicas de identidad, vol. 7 / Dic. 2012, pág. 145. residencia fue mostrado el 17 de septiembre de 2009 dentro de los Encuentros Internacionales de Juventud de Cabueñes. Los artistas asturianos que colaboraron en el proyecto fueron Donkey-boy, Echtra, Penca Catalogue y Blezna, .tape., Komatsu, Mauri, Ramón Prada y Da Robotz quienes produjeron entre otras cosas un CD con el resultado de sus exploraciones sonoras. El mapa sonoro continúa en Asturias, pero el debilitamiento de LABoral como institución clave para el apoyo a la creación asturiana, ha afectado también a la producción de este tipo de arte.

\section{Conclusiones}

El arte sonoro asturiano, supuso un ámbito más de experimentación creativa que vino con la modernización y tecnologización del arte contemporáneo en Asturias durante el siglo XXI. Compartiendo características con paradigmas internacionales, la mayor parte de las muestras más significativas estuvieron relacionadas con Laboral Centro de Arte y Creación Industrial y con los eventos Arenas Movedizas y LEV Festival, espacios que, en su búsqueda de incorporar nuevos lenguajes a la escena artística, no dudaron en acoger y promover las propuestas de carácter sonoro. Dentro de este abanico destacaron dos disciplinas, la instalación sonora y el paisaje sonoro que se nutría de las posibilidades de la tecnología de grabación de campo y el interés por traducir el espectro sonoro a cuestiones de mayor calado cultural. La situación actual de LABoral ha frenado quizá el impulso que hace casi una década dinamizaba todo tipo de propuestas creativas en la región. Aunque actualmente la creación asturiana se mantiene y hereda el cambio impulsado por una época dorada de gran apoyo y contacto con otros artistas y obras del exterior, se sigue notando un mal momento para el arte y la cultura en Asturias. No obstante, reiterando la importancia de la herencia, la transformación del arte y el artista asturiano contemporáneo, es una realidad y da pie al optimismo de pensar en la fortaleza de una escena que debe seguir creciendo. 